\title{
Presymptomatic Transmission and Diverse Progression of Familial Clustering Covid-19 Cases in Zhoushan, China
}

\author{
Miao Liu \\ Putuo Center for Disease Control and Prevention

\section{Leijie Liu} \\ Putuo Centers for Disease Control and Prevention
}

\section{Ping Li}

Second Military Medical University

\section{Yibo Ding}

Second Military Medical University

\section{Ting Wu}

Second Military Medical University

\section{Weina Tang}

Second Military Medical University

\section{Zhongfa Wang}

Putuo Center for Disease Control and Prevention

\section{Guangwen Cao ( $\nabla$ gcao@smmu.edu.cn )}

Second Military Medical University https://orcid.org/0000-0002-8094-1278

\section{Research}

Keywords: Presymptomatic transmission, family cluster, SARS-CoV-2, COVID-19

Posted Date: July 20th, 2020

DOI: https://doi.org/10.21203/rs.3.rs-44177/v1

License: (1) This work is licensed under a Creative Commons Attribution 4.0 International License. Read Full License 


\section{Abstract \\ Background}

Novel coronavirus disease 2019 (COVID-19), severe acute respiratory syndrome coronavirus 2 (SARS-CoV-2)caused emerging infectious disease, firstly identified in Wuhan (Hubei, China), is pandemic. However, data concerning presymptomatic SARS-CoV-2 transmission and disease diversity among family members are limited. Herein, We investigated the epidemiological and clinical characteristics of presymptomatic transmission-caused familial clustering cases of SARS-CoV-2 infection in Zhoushan island, China.

\section{Methods}

All family members were tested for SARS-CoV-2 genomic RNA by quantitative reverse transcription PCR in 3 different samples and serum antibody immunoglobin M (IgM) and IgG against SARS-CoV-2. Exposure identification, laboratory test, and imaging were performed according to the national guideline of COVID-19 (7th edition, China).

\section{Results}

Of the 6 cases, index case who ever met his relative with COVID-19 from Xianning, Hubei on January 26-31, 2020, transmitted SARS-CoV-2 to his family members in Zhoushan via visiting family during January 31 and February 3, 2020. The index was identified as common-type COVID-19 on February 6, 2020. All 5 family members were infected with SARS-CoV-2. Of those, a 7-year-old girl was an asymptomatic carrier whereas her grandparents, especially her grandfather, were very sick. Case 6 (grandfather) remained positive for SARSCoV-2 RNA in his sputum specimen in subsequent 2 months. Case 2 (mother) tested negative for SARS-CoV-2 RNA in all samples but positive for IgM and IgG to SARS-CoV-2 since February 9, 2020.

\section{Conclusions}

Presymptomatic transmission of SARS-CoV-2 causes familial cluster of COVID-19. Exposed to the same source of infection, family members present their differences in disease severity and viral clearance.

\section{Introduction}

Novel coronavirus disease in 2019 (COVID-19) caused by severe acute respiratory syndrome coronavirus 2 (SARS-CoV-2) has being pandemic since it was firstly identified in Wuhan, China, in late December 2019 [1]. The case number keepsincreasing. As of June 9, 2020, the global confirmed COVID-19 cases and deaths increased to 7039918 and 404396, respectively [2].Family clustering and hospital-based transmission were the two major epidemiological features of this outbreak at the early stage, and continued to be an important cause of community-based SARS-CoV-2 transmission in a low prevalence region [3-8]. However, data 
concerning SARS-CoV-2 transmissibility in the incubation period and the diversity in disease progression among affected family members are very limited.

To provide the information for recognizing the transmissibility of SARS-COV-2 in the incubation period, we studied the epidemiological, immunological, and clinical characteristics of family clustering COVID-19 cases in Zhoushan, an archipelago with a population of 1.152 million inEastern Zhejiang province of China.

\section{Methods}

\section{Familial clustering of COVID-19}

From February 6 to February 12, 2020, Municipal Center for Disease Control and Prevention (CDC) of Zhoushan received a report that 6 individuals within a family might be infected with SARS-CoV-2. We then carried out a field epidemiological study to investigate their exposure history and clinical data and then followed up these patients to obtain complete information. Diagnoses and clinical typing of COVID-19 were carried out according to the protocol for the diagnosis and treatment of COVID-19 (Version 7th), National Health Commission of the People's Republic of China [9]. Briefly, COVID-19 was diagnosed if the patient's nasal and throat swab, fecal sample, or sputum sample was tested positive for SARS-CoV-2 genomic RNA. All diagnosed COVID-19 patients were classified as mild, common, severe, and extremely severe types. This study was approved by the Ethics Commission of Second Military Medical University. Written informed consent was waived for emerging infectious diseases.

\section{Epidemiological survey}

A semi-structured questionnaire was applied to obtain demographic information, exposure information of the familiar clustering cases via face-to-face interview and telephone calls by well-trained professionals. The data regarding any travel history to Wuhan of Hubei province and other areas with COVID-19 epidemic, contact with confirmed cases or asymptomatic carriers tested positive for SARS-CoV-2 genomic RNA, contact with patients with some symptoms like fever, cough, and expectoration in the past 2-3 weeks before illness onset. Any chance and duration of attending any kinds of population gatherings were recorded as well.

\section{Clinical and radiographic data}

Clinical information included the date of symptom onset and admission to designated hospitals, clinical manifestation, routine laboratory examinations, and radiographic examinations. The clinical manifestation, chest computed tomography (CT) images, and laboratory results were collected from the electronic medical record systems in the two designated hospitals: Zhoushan Maternal and Child Health Care Hospital and Putuo Hospital. Two researchers independently reviewed all of the data to doubly check the accuracy of data collected. Patients were regularly followed-up to the last days when they were all negative for 3 consecutive tests.

\section{Detection of SARS-CoV-2 genomic RNA}

Quantitative reverse transcription-PCR (qRT-PCR) assay was applied to detect SARS-CoV-2 genomic RNA in nasal and throat swabs, sputum, and feces of patients. Two targets, the open reading frame 1ab (ORF1ab) 
and nucleoprotein $(\mathrm{N})$ genes of SARS-COV-2 were detected using the testing kits manufactured by Shanghai GeneoDx Biotech Company (Shanghai, China) [10]. Sample was positive if the cycling threshold (CT) values of both ORF1ab and $\mathrm{N}$ genes were less than 37 . Sample was negative if no CT value, or CT value of greater than 40 , or unrepeatable CT value in the range of $37-40$.

\section{Detection of antibodies against SARS-COV-2}

Immunoglobulin M (IgM) and immunoglobulin G (IgG)to SARS-CoV-2 in the frozen reserved fasting serum samples was detected using the diagnostic kit for human IgM \& IgG detection of SARS-CoV-2 (enzyme-linked immunosorbent assay), which was manufactured by Nanjing Wending Biotech Company (Nanjing, China). Specifically, IgM and IgG antibodies against the recombinant nucleocapsid protein of SARS-CoV-2 were qualitatively detected by mouse anti-human IgM-horseradish peroxidase (HRP) and IgG-HRP secondary antibody, respectively. Sample was positive if theratio of optical density (OD) to the cut-off value (CO) was equal or greater than 1 and negative if the ratio was less than 1. A higher OD/CO value indicated a higher level of antibody concentration.

\section{Results}

\section{Epidemiology}

The familial clustering cases consists of 6 SARS-CoV-2-infected family members: case 1 (index), case 2(wife of case 1), case 3(daughter of cases 1 and 2), case 4 (sister-in-law of index), case 5(mother-in-lawof index), and case 6 (father-in-law of index). Of this familial cluster, 5 were laboratory-confirmed COVID-19 cases and one was asymptomatic carrier.

Case 1 had been working in Wuxi city, Jiangsu province of China. During January 26 and January 31, 2020, he contacted with one of his relatives, a confirmed COVID-19 patient from Xianning city, Hubei, China. On January 31,2020 , he went back to Zhoushan and lived with six family members from January 31 to February 3, 2020. Then, case 1 left Zhoushan to Wuxi on February 3, 2020. On February 6, case 1 got pneumonia andwas tested positive for SARS-COV-2 genomic RNA in Wuxi. Putuo CDC was then informed by Wuxi CDC to quarantine his family members. After being quarantined in Zhoushan on February 8, 2020, the 5family members were examined for the presence of SARS-COV-2 by qRT-PCR.Apart from case 2, cases 3, 4, 5, and 6 were tested positive for SARS-COV-2 and then transferred to the designated hospitals at that night. On the next day, chest CT showed pulmonary inflammation and ground-glass opacity in cases 4,5 , and 6 , rather than in case 3. Case 2 was negative for SARS-COV-2 genomic RNA but positive for IgG and IgM. She was then subjected to take chest CT scanning for further diagnosis. Due to the sign of pulmonary infection, she was admitted to Putuo hospital as well. According to epidemiological investigation by Zhoushan CDC, cases 2, 3, 4, 5, and 6lived together all the time and never left Zhoushan at the last 2-3 weeks before onset of illness. During this period, they had not contacted with other COVID-19 patients, patients with respiratory symptoms, and any wild animal. The chronology of family relationship, exposure history, symptomonset, and identification of SARS-CoV-2 genomic RNA and antibodies findingsare presented in Figure 1.

\section{Clinical, and radiographic findings}


Case 1, a 41-year-old man, was diagnosed as COVID-19 of the common-type. He got pneumonia and then hospitalized on February 6, 2020. Case 2, a 41-year-old woman, presented positive pneumonia CT image at admission and was ever febrile during hospital stay (February 9 to February 28, 2020). She was also diagnosed as common-type COVID-19. Case 3, a 7-year-old girl, was asymptomatic carrier. She was positive for SARS-CoV-2 genomic RNA on February 9, 2020, but free of anyclinical manifestation. CT images and laboratory parameters of this girl were normal as well. Case 4 was a 42-year-old woman who wasdiagnosed as common-type COVID-19. She developed fever, cough, and diarrhea at admission. On March 17, 2020, she was discharged from hospital and tested positive for IgM and IgG antibodies to SARS-CoV-2. Case 5, a 64year-old woman, developed common-type COVID-19. Expectoration was the only symptom. Routine blood test showed lower saturation of haemoglobinoxygen saturation. On February 17, 2020, illness of case 5 progressed but did not meet the criteria of severe-type COVID-19. Case 6, a 66-year-old man, had the most serious COVID-19 and the longest duration of hospitalization of this familiar cluster. He was mild at the early stage of hospital stay (February 10-16, 2020), but progressed rapidly to be severe COVID-19. He suffered apparent clinical symptoms since illness onset, including fever, productive cough, diarrhea, and dyspnoea. Except case 3, the asymptomatic carrier, all cases had abnormal chestCT images, indicating pneumonia was present at admission (Table 1).

\section{Dynamics in pathogenic and serological findings}

Pathogenic and serological tests were regularly conducted during hospital stay and follow-up period. However, cases 1 and 5 refused to be followed-up. Thus the continuous data of the two patients were lacking. For case 3, viral load of SARS-CoV-2 in fecal samples, reflected by the CT values of qRT-PCR, declined gradually during hospital stay and follow-up period. On March 17, 2020, the OD/CO value of IgM and IgG antibodies to SARS-COV-2 in case 3 were 1.05 and 3.96, respectively. Case 4 was positive for IgM and IgG antibodies to SARS-COV-2 and negative for SARS-COV-2 genomic RNA at her last follow-up on March 17, 2020. Case 6 remained positive for SARS-CoV-2 genomic RNA in his sputum specimens,rather than in throat swabs and fecal specimens, during February 17 and April 8, 2020, thereafter he was tested negative for 3 consecutive times at 1 day interval.

Interestingly, case 2 was admitted to hospital due to her positive CT image. She was negative for SARS-CoV-2 viral RNA in throat swabs, sputum samples, and fecal samples. Meanwhile, the titers of serum IgM and IgG antibodies to SARS-CoV-2 kept increasingduring hospital stay and follow-up period from February 9 to March 24. The OD/CO ratio of IgM increased from 1.02 to 8.06 and the ratio of IgG increased from 1.50 to 4.62 . The titers of IgM and IgG antibodies increased again after decreased on March 8, 2020 (Figure 2). Thus, case 2 might recovered from COVID-19 before centralized isolation in hospital and then be exposed to SARS-CoV-2 again, possibly from her affected family members.

\section{Discussion}

In this study, we reported introduced family clustering cases of COVID-19 in a relative isolated archipelago in Eastern China where COVID-19 was rarely introduced. Our epidemiological evidence chain clearly showed that an index case got the infection of SARS-CoV-2 from his sick relative from Hubei province and transmitted SARS-CoV-2 to all of his family members in Zhoushan in his presymptomatic incubation period. This way of 
transmitting the deadly virus is of great epidemiological significance because the family members are usually unaware of the coming danger, thus being hard to take actions for the prophylaxis. Different coronaviruses have different transmission dynamics. Transmission of severe acute respiratory syndrome-related coronavirus (SARS-CoV) occurred mainly in the second week of illness when viral load in the upper airway peaks on day 10 of illness [11]. The incubation of SARS-CoV was 4 days on average [12]. That means SARS$\mathrm{CoV}$ is unlikely to transmit within its incubation period. SARS-CoV-2 transmits more quick than do SARS-CoV [13]. Although the kinetics of transmission remains unknown, SARS-CoV-2 should replicate quickly in the sensitive cells and reach the level of causing horizontal transmission before clinical manifestation. Thepresymptomatic transmission of SARS-CoV-2, especially in the terminal stage of incubation period, was also evident in other non-epidemic zones [14-18]. This might be one of the reasons why the intra-familial transmission contributed to approximately $75 \%$ of SARS-CoV-2 transmission eventsin a low prevalence region [19]. It was reported that presumed asymptomatic carrier transmitted COVID-19 [20-23]. However, the most (approximately 70\%) of asymptomatic SARS-CoV-2 carriers either progressed into "symptomatic" or developed the typical CT images of pneumonia [21]. The most asymptomatic transmission could be classified as presymptomatic transmission in the incubation period. Thus, transmission of COVID-19 in the incubation period should be an important mode of infection for the prevention and control of SARS-CoV-2 transmission worldwide, especially in a low prevalence region.

In this family cluster of COVID-19, the seven-year-old girl and her grandparents were exposed to the same source of infection. However, they had diverse clinical manifestations: this girl was asymptomatic whereas her grandparents, especially her grandfather, were very sick. This observation is quite in consistent with the findings of large epidemiological studies. Children who get SARS-CoV-2 infection mostly have mild respiratory symptoms or are asymptomatic [24].Elderly patients with COVID-19, especially male patients, are more likely to progress into severe-type and even die of this disease $[25,26]$. Thus, difference in the immune response to the same SARS-CoV-2 virus between children and elderly male patients should be essential in elucidating the mechanisms by which severe COVID-19 is generated.

Case 2, wife of the index case, presented with interesting clinical and laboratory findings. She might be infected on January 31, 2020 and presented with a pneumonia-specific chest CT image after hospitalization on February 9, 2020. However, this patient was tested negative for SARS-CoV-2 in all available samples but the titers of IgM and IgG antibodies to SARS-CoV-2 kept increasing from February 9 to March 8, 2020, indicating that SARS-CoV-2 in case 2 had been quickly eradicated by host anti-viral immunity. Interestingly, the titers of IgM and IgG antibodies increased again after decreased on March 8, 2020, possibly because she was re-exposed to SARS-CoV-2, possibly from her affected family member(s) when she took care of them.

\section{Conclusions}

SARS-CoV-2 can be efficientlytransmitted to family members in the incubation period, especially in the terminal stage of incubation, via close contact. This mode of infection is extremely important in understanding COVID-19 epidemiology in low prevalence regions. Family members who exposed to the same source of infection have a diverse clinical process, ranging from asymptomatic carrier to severe-type COVID19. This study is of public health importance in the prevention and control of COVID-19 pandemic, especially in a low prevalence region. 


\section{List Of Abbreviations}

COVID-19: coronavirus disease 2019; SARS-CoV-2: severe acute respiratory syndrome coronavirus 2; qRT-PCR: Quantitative reverse transcription-PCRassay; IgM: Immunoglobulin M; IgG: immunoglobulin G.

\section{Declarations}

\section{Acknowledgments}

We acknowledge all health-care workers involved in the diagnosis and treatment of patients in Zhoushan. We thank Putuo CDC for providing data for patients with SARS-CoV-2.

\section{Ethics approval and consent to participate}

This study was approved by the Ethics Commission of Second Military Medical University. All subjects volunteered to participate in the study.

\section{Availability of data and materials}

The authors confirm that the data supporting the findings of this study are available within the article.

\section{Competing interests}

The authors declare that they have no competing interests

\section{Consent for publication}

Written informed consent was waived for emerging infectious diseases.

\section{Funding}

This study was supported by grants from Science and Technology Commission Shanghai Municipality (No. 20JC1410200; 20431900404), Science and Technology Bureau of Putuo district, Zhoushan Municipality (No. 2020GY306), and National Natural Science Foundation of China (82041022).

\section{Authors' contributions}

Miao Liu: investigation, funding acquisition, data organization. Leijie Liu: investigation, etiological identification, antibody test. Ping Li: data analysis, composition of figures and table. Yibo Ding: data analysis. Ting Wu: project management. Weina Tang, data entry and analysis. Zhongfa Wang: supervision on laboratory test and etiological identification. Guangwen Cao: conceptualization, investigation, supervision, funding acquisition, writing - original draft.

\section{References}

1. Chen N, Zhou M, Dong X,Qu J, Gong F,Han Y, et al.Epidemiological and clinical characteristics of 99 cases of 2019 novel coronavirus pneumonia in Wuhan, China: a descriptive study. Lancet. 2020;395(10223):507- 
2. WHO. Coronavirus disease 2019 (COVID-19) Situation Report-141. https://www.who.int/docs/defaultsource/coronaviruse/situation-reports/20200609-covid-19-sitrep-141.pdf?sfvrsn=72fa1b16_2

3. Chan JF, Yuan S, Kok KH,To KK, Chu H,Yang J, et al. A familial cluster of pneumonia associated with the 2019 novel coronavirus indicating person-to-person transmission: a study of a family cluster. Lancet. 2020;395(10223):514-523. doi:10.1016/S0140-6736(20)30154-9

4. Kluytmans-van den Bergh MFQ, Buiting AGM, Pas SD. Prevalence and Clinical Presentation of Health Care Workers With Symptoms of Coronavirus Disease 2019 in 2 Dutch Hospitals During an Early Phase of the Pandemic. JAMA Netw Open. 2020;3(5):e209673. Published 2020 May 1.

doi:10.1001/jamanetworkopen.2020.9673

5. Xia XY, Wu J, Liu HL, Xia H, Jia B, Huang WX. Epidemiological and initial clinical characteristics of patients with family aggregation of COVID-19. J Clin Virol. 2020;127:104360. doi:10.1016/j.jcv.2020.104360

6. Gonzalez-Reiche AS, Hernandez MM, Sullivan MJ. Introductions and early spread of SARS-CoV-2 in the New York City area [published online ahead of print, 2020 May 29]. Science. 2020;eabc1917. doi:10.1126/science.abc1917

7. Qiu C, Deng Z, Xiao Q, Shu Y,Deng Y,Wang H,et al. Transmission and clinical characteristics of coronavirus disease 2019 in 104 outside-Wuhan patients, China [published online ahead of print, 2020 May 5]. J Med Virol. 2020;10.1002/jmv.25975. doi:10.1002/jmv.25975

8. Ghinai I, Woods S, Ritger KA. Community Transmission of SARS-CoV-2 at Two Family Gatherings - Chicago, Illinois, February-March 2020. MMWR Morb Mortal Wkly Rep. 2020;69(15):446-450. Published 2020 Apr 17. doi:10.15585/mmwr.mm6915e1

9. National Health Commission of the People's Republic of China. Diagnosis and Treatment Protocol for COVID-19 (Trial Version 7). (updated: 2020-03-29) Available from: http://en.nhc.gov.cn/202003/29/c_78469.htm

10. Shen C, Wang Z, Zhao F, Yang Y,Li J,Yuan J,et al. Treatment of 5 Critically III Patients With COVID-19 With Convalescent Plasma [published online ahead of print, 2020 Mar 27]. JAMA. 2020;323(16):1582-1589. doi:10.1001/jama.2020.4783

11. Hui DS, Memish ZA, Zumla A. Severe acute respiratory syndrome vs. the Middle East respiratory syndrome. Curr Opin Pulm Med. 2014;20(3):233-241. doi:10.1097/MCP.0000000000000046

12. Avendano M, Derkach P, Swan S. Clinical course and management of SARS in health care workers in Toronto: a case series. CMAJ. 2003;168(13):1649-1660.

13. Liu Y, Gayle AA, Wilder-Smith A, Rocklöv J. The reproductive number of COVID-19 is higher compared to SARS coronavirus. J Travel Med. 2020;27(2):taaa021. doi:10.1093/jtm/taaa021 
14. Li P, Fu JB, Li KF, Liu JN,Wang HL,Liu LJ,et al. Transmission of COVID-19 in the terminal stage of incubation period: a familial cluster [published online ahead of print, 2020 Mar 16]. Int J Infect Dis. 2020;96:452-453. doi:10.1016/j.ijid.2020.03.027

15. Tong ZD, Tang A, Li KF, Li P,Wang HL,Yi JP,et al. Potential Presymptomatic Transmission of SARS-CoV-2, Zhejiang Province, China, 2020. Emerg Infect Dis. 2020;26(5):1052-1054. doi:10.3201/eid2605.200198

16. Li C, Ji F, Wang L, Wang L,Hao J,Dai M,et al. Asymptomatic and Human-to-Human Transmission of SARSCoV-2 in a 2-Family Cluster, Xuzhou, China [published online ahead of print, 2020 Mar 31]. Emerg Infect Dis. 2020;26(7):10.3201/eid2607.200718. doi:10.3201/eid2607.200718

17. Zhang W, Cheng W, Luo L,Ma Y,Xu C,Qin P, et al. Secondary Transmission of Coronavirus Disease from Presymptomatic Persons, China [published online ahead of print, 2020 May 26]. Emerg Infect Dis. 2020;26(8):10.3201/eid2608.201142. doi:10.3201/eid2608.201142

18. Qian G, Yang N, Ma AHY,Wang L, Li G,Chen X,et al. A COVID-19 Transmission within a family cluster by presymptomatic infectors in China [published online ahead of print, 2020 Mar 23]. Clin Infect Dis. 2020;ciaa316. doi:10.1093/cid/ciaa316

19. Cao C, Li Y, Liu S, Fan H, Hao L. Epidemiologic Features of 135 Patients With Coronavirus Disease (COVID19) in Tianjin, China [published online ahead of print, 2020 Apr 1]. Disaster Med Public Health Prep. 2020;1-5. doi:10.1017/dmp.2020.63

20. Bai Y, Yao L, Wei T, Tian F, Jin DY, Chen L, et al. Presumed Asymptomatic Carrier Transmission of COVID19 [published online ahead of print, 2020 Feb 21]. JAMA. 2020;323(14):1406-1407. doi:10.1001/jama.2020.2565

21. Hu Z, Song C, Xu C, Jin G,Chen Y,Xu X,et al. Clinical characteristics of 24 asymptomatic infections with COVID-19 screened among close contacts in Nanjing, China. Sci China Life Sci. 2020;63(5):706-711. doi:10.1007/s11427-020-1661-4

22. Huff HV, Singh A. Asymptomatic transmission during the COVID-19 pandemic and implications for public health strategies [published online ahead of print, 2020 May 28]. Clin Infect Dis. 2020;ciaa654. doi:10.1093/cid/ciaa654

23. Ford JS, Parikh A, Sandhu R, Turnipseed S,Morris B,May L,et al. Testing Asymptomatic Emergency Department Patients for Coronavirus of 2019 (COVID-19) in a Low Prevalence Region [published online ahead of print, 2020 Jun 9]. Acad Emerg Med. 2020;10.1111/acem.14044. doi:10.1111/acem.14044

24. Castagnoli R, Votto M, Licari A, Brambilla I,Bruno R,Perlini S,et al. Severe Acute Respiratory Syndrome Coronavirus 2 (SARS-CoV-2) Infection in Children and Adolescents: A Systematic Review [published online ahead of print, 2020 Apr 22]. JAMA Pediatr. 2020;10.1001/jamapediatrics.2020.1467. doi:10.1001/jamapediatrics.2020.1467 
25. Liu K, Chen Y, Lin R, Han K. Clinical features of COVID-19 in elderly patients: A comparison with young and middle-aged patients. $J$ Infect. 2020;80(6):e14-e18. doi:10.1016/j.jinf.2020.03.005

26. Grasselli G, Zangrillo A, Zanella A, Antonelli M , Cabrini L, Castelli A, et al. Baseline Characteristics and Outcomes of 1591 Patients Infected With SARS-CoV-2 Admitted to ICUs of the Lombardy Region, Italy [published online ahead of print, 2020 Apr 6]. JAMA. 2020;323(16):1574-1581. doi:10.1001/jama.2020.5394

\section{Tables}

Table 1. Epidemiological, clinical features, pathogen and serological results of the family cluster infected with SARS-CoV-2 


\begin{tabular}{|c|c|c|c|c|c|c|}
\hline & $\begin{array}{l}\text { Case } \\
1\end{array}$ & Case 2 & Case 3 & Case 4 & Case 5 & Case 6 \\
\hline Age (years) & 41 & 41 & 7 & 42 & 64 & 66 \\
\hline Gender & Male & Female & Female & Female & Female & Male \\
\hline \multicolumn{7}{|l|}{ Travel history } \\
\hline Wuxi & + & - & - & - & - & - \\
\hline Zhoushan & + & + & + & + & + & + \\
\hline \multicolumn{7}{|l|}{$\begin{array}{l}\text { Contact } \\
\text { history }\end{array}$} \\
\hline $\begin{array}{l}\text { Confirmed } \\
\text { patients }\end{array}$ & + & + & + & + & + & + \\
\hline Wild animal & - & - & - & - & - & - \\
\hline $\begin{array}{l}\text { Domestic } \\
\text { animals }\end{array}$ & - & - & - & - & - & - \\
\hline $\begin{array}{l}\text { Interval } \\
\text { between } \\
\text { exposure and } \\
\text { symptom } \\
\text { onset (days) }\end{array}$ & 11 & 11 & - & 9 & 9 & 9 \\
\hline $\begin{array}{l}\text { Interval } \\
\text { between } \\
\text { symptom } \\
\text { onset and } \\
\text { hospitalization } \\
\text { (days) }\end{array}$ & 0 & 1 & - & 0 & 0 & 0 \\
\hline \multicolumn{7}{|l|}{$\begin{array}{l}\text { Main } \\
\text { symptoms }\end{array}$} \\
\hline Fever & - & + & - & + & - & + \\
\hline Cough & - & - & - & $+(\mathrm{dry})$ & +(productive) & $+($ productive) \\
\hline $\begin{array}{l}\text { Short of } \\
\text { breath }\end{array}$ & - & - & - & - & - & + \\
\hline Diarrhoea & - & - & - & + & - & - \\
\hline \multicolumn{7}{|l|}{$\begin{array}{l}\text { Pathogen and } \\
\text { Serological } \\
\text { tests at } \\
\text { admission }\end{array}$} \\
\hline \multicolumn{7}{|l|}{$\begin{array}{l}\text { qRT-PCR-CT } \\
\text { values }\end{array}$} \\
\hline Throat swab & NA & 0.00 & 22.00 & 0.00 & NA & 0.00 \\
\hline $\begin{array}{l}\text { Sputum } \\
\text { specimen }\end{array}$ & NA & 0.00 & NA & 0.00 & NA & 30.63 \\
\hline
\end{tabular}




\begin{tabular}{|lllllll|}
\hline $\begin{array}{l}\text { Fecal } \\
\text { specimen }\end{array}$ & NA & 0.00 & 36.61 & 0.00 & NA & 0.00 \\
$\begin{array}{l}\text { OD/CO of anti- } \\
\text { IgM }\end{array}$ & NA & 0.29 & NA & 16.11 & NA & 32.26 \\
\hline $\begin{array}{l}\text { OD/CO of anti- } \\
\text { IgG }\end{array}$ & NA & 0.25 & NA & 19.15 & NA & 25.62 \\
$\begin{array}{l}\text { Chest } \\
\text { radiography } \\
\text { findings }\end{array}$ & Present & Present & Absent & Present & Present & Present \\
$\begin{array}{l}\text { Clinical } \\
\text { classification } \\
\text { of COVID-19 }\end{array}$ & common & common & asymptomatic carrier & common & common & severe \\
\hline
\end{tabular}

CT, cycling threshold; OD/CO, optical density/cut-off value; COVID-19, novel coronavirus disease in 2019; NA, not available; +, positive;-, negative.

\section{Figures}

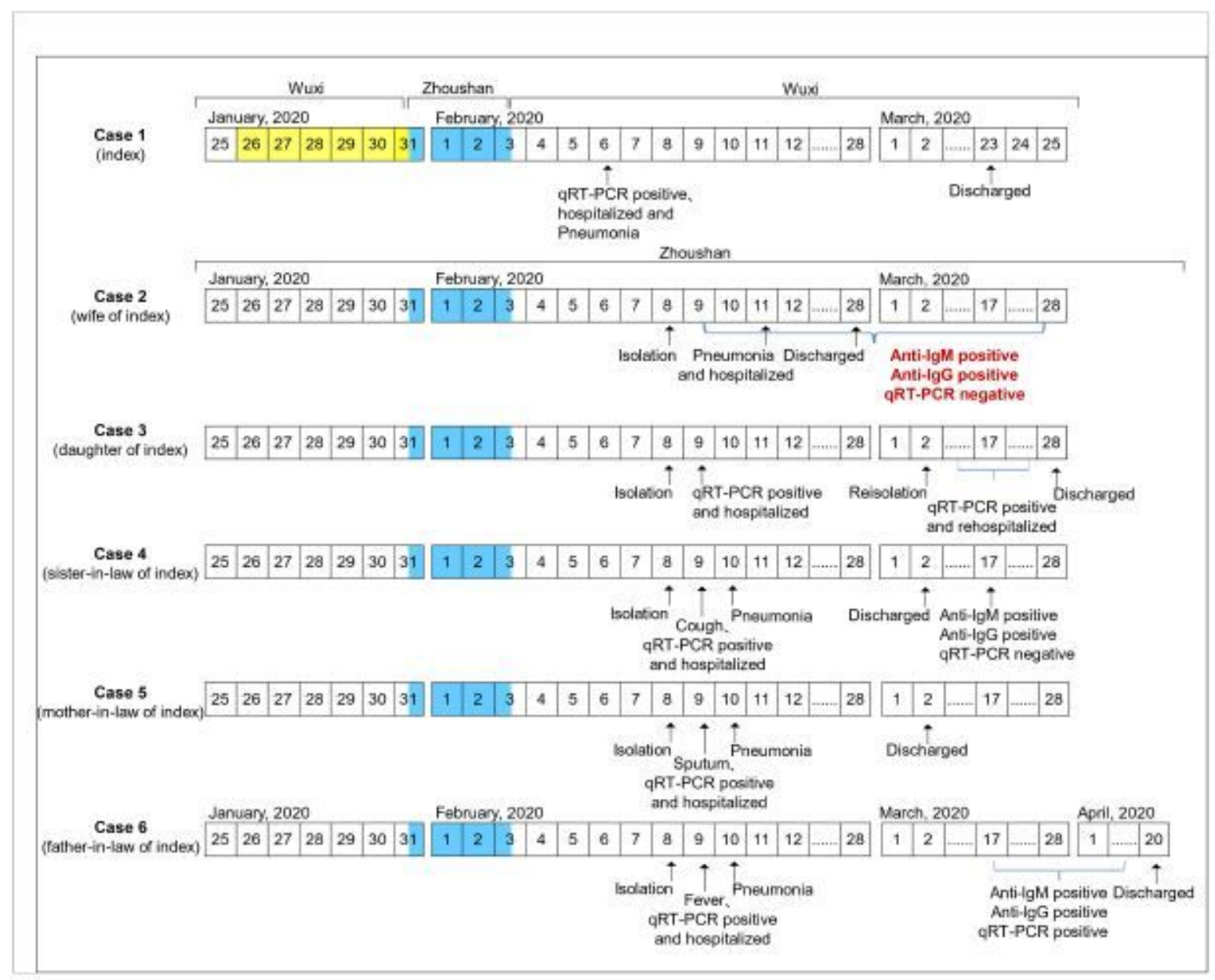


Chronology of symptom onset of the family cluster and their contacts in Zhoushan, China Dates filled in yellow are the duration that case 1 had close contacts with his COVID-19 relative. Dates filled in blue are the duration the 6 cases lived together.

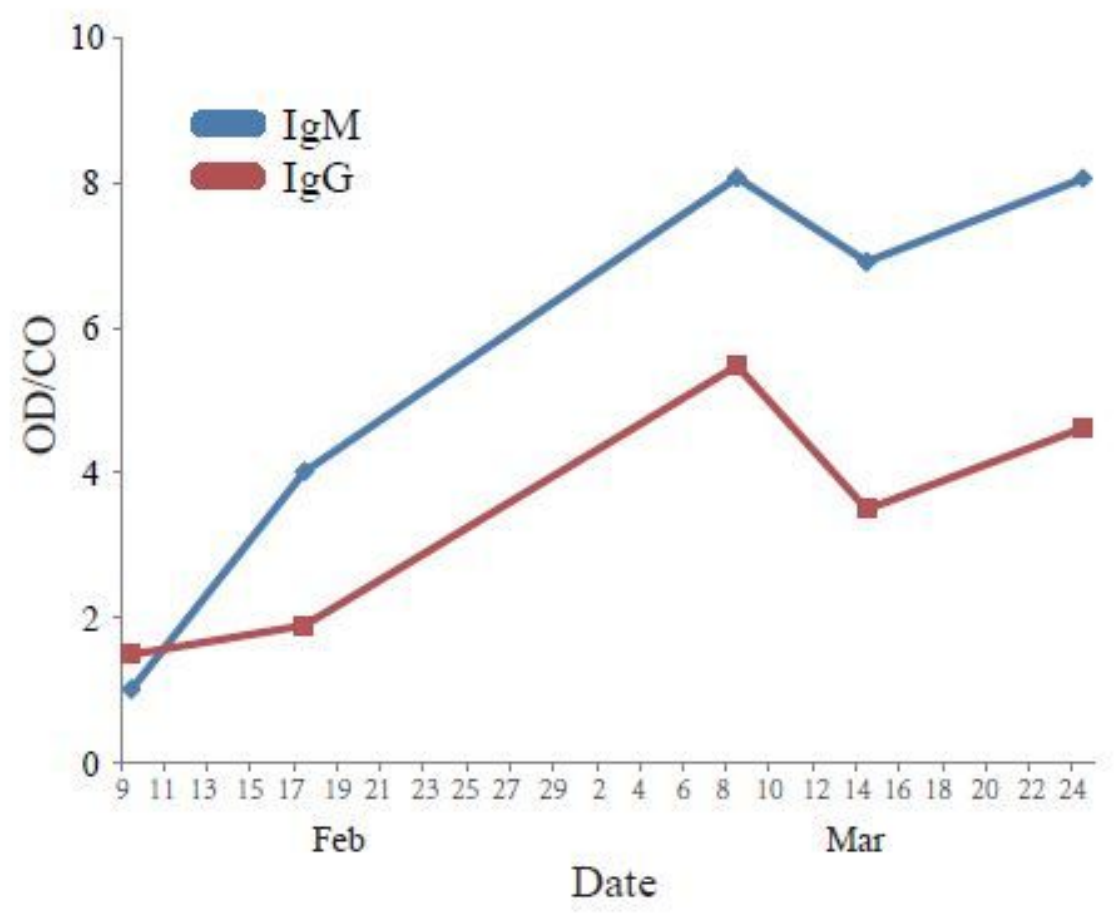

Figure 2

The trend of IgM and IgG antibody levels in case 2 from February 9 to March 24, 2020 